\title{
Developing Physical Education Learning Model to Promote Active Lifestyle
}

\author{
Dian Budiana*, Gano Sumarno, Cep Ubad Abdullah \\ Fakultas Pendidikan Olahraga dan Kesehatan \\ Universitas Pendidikan Indonesia \\ Bandung, Indonesia \\ *dianbudiana@upi.edu
}

\begin{abstract}
This study aimed to find out the physical activity index of elementary school students in Bandung, Indonesia. Three schools with different clustering levels (high, medium, and low) were chosen and their students were requested to fill out questionnaire regarding nutrition, physical activity at schools, and physical activity after school. The results showed that most of the respondents in this study lacked necessary nutrition, physical activity at school, and physical activity at home. It is expected that this index can be good consideration to develop a curriculum promoting healthy and active lifestyle since it is one of the most important aspects of lifelong physical activity.
\end{abstract}

Keywords—physical education; learning model; active lifestyle

\section{INTRODUCTION}

Physical education is a part of general educational program that contributes, primarily through movement experiences, to the total growth and development of all children. Physical education is defined education of and through movement, and must be conducted in a manner that merit this meaning.

Pate argues that schools have the potential to be attractive places to stimulate healthy behavior because students spend most of their time in the school environment [1]. Therefore, a curriculum that supports active lifestyle activities, such as a curriculum that provides extracurricular programs related to physical activity, is strongly recommended [1]. Furthermore, Ciotto argues that the curriculum must stimulate students to be able to foster a culture of movement before, during, and after school [2]. Thus, students will have a long-term effect on an active lifestyle curriculum. Each student will naturally plan and carry out physical activities even though they are not in the school environment.

In addition to the professional quality of physical education teachers, the quality of Penjas learning also needs to be developed in such a way as to adapt to the situation and conditions so that it can solve various problems that exist today. One of the most crucial problems at the moment is the low level of fitness of the Indonesian people, which is one of the causes because of the low active life behavior. Therefore, through physical education it is hoped that it can improve the active behavior of the Indonesian people so that in the end it can improve the quality of life of this nation.
Some studies have shown that physical education must drive a healthy and active lifestyle so students prepare for lifelong physical activity $[3,4]$. In other words, students are prepared with capable knowledge and abilities so that they, both junior and senior high school students, can implement these knowledge and abilities in lifelong physical activity [5].

In order to prepare Indonesian people to face the challenges and demands of the globalization era, namely "Future Shock" [6] and acceleration of changes in various fields of life that occur quickly as a result of scientific change and technological revolution, hence in the context of education especially physical education in schools it is necessary to develop a learning model that is conditional on active lifestyle values of active life behavior or behavior as a preventive action in order to be able to adapt to existing conditions.

Therefore, physical education as a process of education about and through the activities of motion "Physical education is defined as education of and movement" [7] seeks to prepare students to continue to behave actively during and after learning physical education

From the description above, in general the problems that the authors want to examine are related to "How the Learning Process of Physical Education in Schools Can Foster Students' Lifelong Active Lifestyle Behaviors". To further clarify the problems studied, the authors describe this problem on several research questions, including; 1) What is the index of physical activity of elementary school students in Bandung; 2) what kind of material substance that needs to be emphasized in the physical education process so that elementary school students have active life behaviors; 3) What learning approach should be applied in the physical education process so that elementary school students have active life behaviors; and 4) How to engineer a physical education learning model that can foster active lifestyle behavior and be able to fulfill pedagogical philosophical criteria that are relevant to student learning needs, substantially academically meet the demands of scientific development and social dynamics now and in the future, and in educational programs easy to apply in the process of physical education? 


\section{RESEARCH MethoD}

This study employed Research and Development method. The research process was carried out in two stages: The first step was to identify the conditions of physical education learning in relation to the use of penjas learning models, difficulties and weaknesses faced, identification of the need to develop value-based learning models to develop students' active lifestyle behaviors and after receiving physical education. In the second phase the model has been refined through a series of seminars (FGD) with related physical education teachers and stakeholders (physical education MGMP (teachers' association of a certain subject), and physical education experts. After that, the improved model has been tested by experiment Based on the results of the experiment, it was obtained that physical education learning model can develop active life behaviors of students during and after receiving Penjas lessons at school. The population in this study were all elementary school students in Bandung and the sample comprised three schools selected through different clustering levels.

\section{RESULTS AND DISCUSSION}

\section{A. Nutrition}

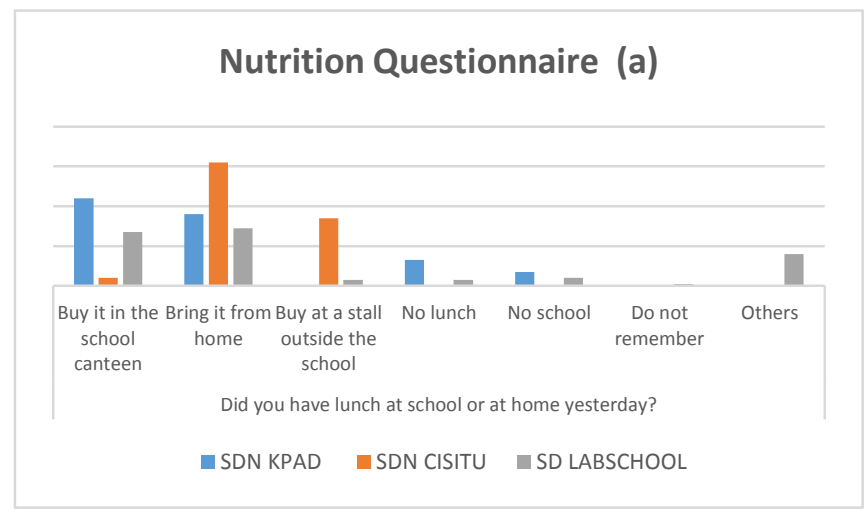

Fig. 1. Questionnaire results on nutrition (a).

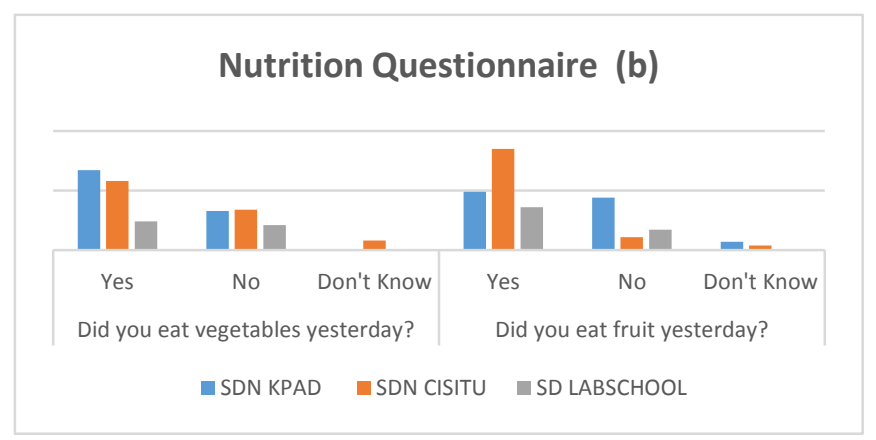

Fig. 2. Questionnaire results on nutrition (b).

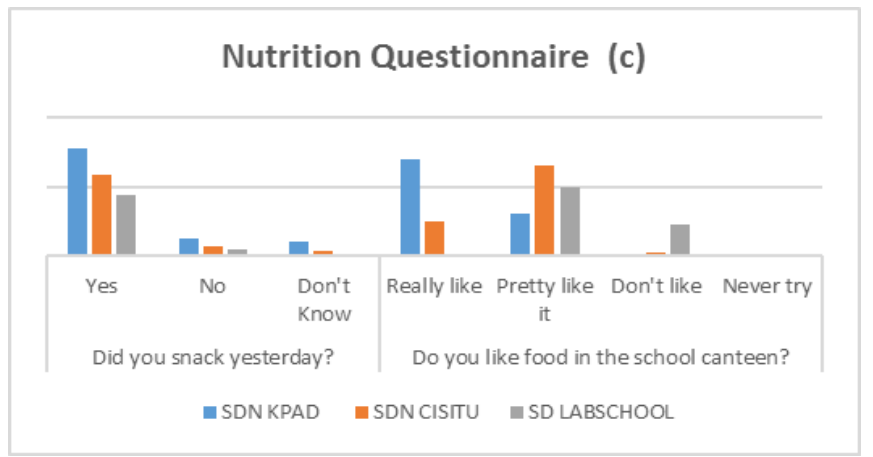

Fig. 3. Questionnaire results on nutrition (c).

From Fig. 1, Fig. 2, and Fig. 3, it can be concluded that most students from all the three schools did not have as ideal amount of nutrition as they actually need. For instance, when there were asked where and how they had lunch, most of them answered that they bought it at the school cafetaria. However, the cafetarias did not provide healthy meals. Most of the dishes they had were fried. In addition, when they were asked whether they had snacks, most of them did have snacks containing a lot of MSG.

In fact, Katz et al. found out that to promote an active and healthy lifestyle in elementary schools, there needs to be a good diet program at school [8]. By having such an effective program, students were able to choose their own healthy food. More importantly, this kind of program should also have a positive impact in their after school life. According to Kelder, an after school habit of choosing the right diet for children in elementary schools is an important aspect of promoting lifelong active lifestyle [9].

\section{B. Physical Activity}

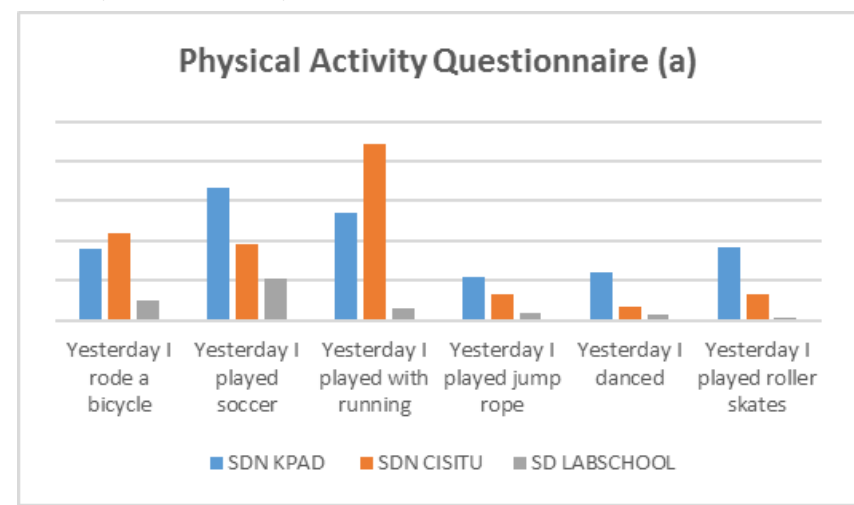

Fig. 4. Questionnaire results on physical activity (a). 


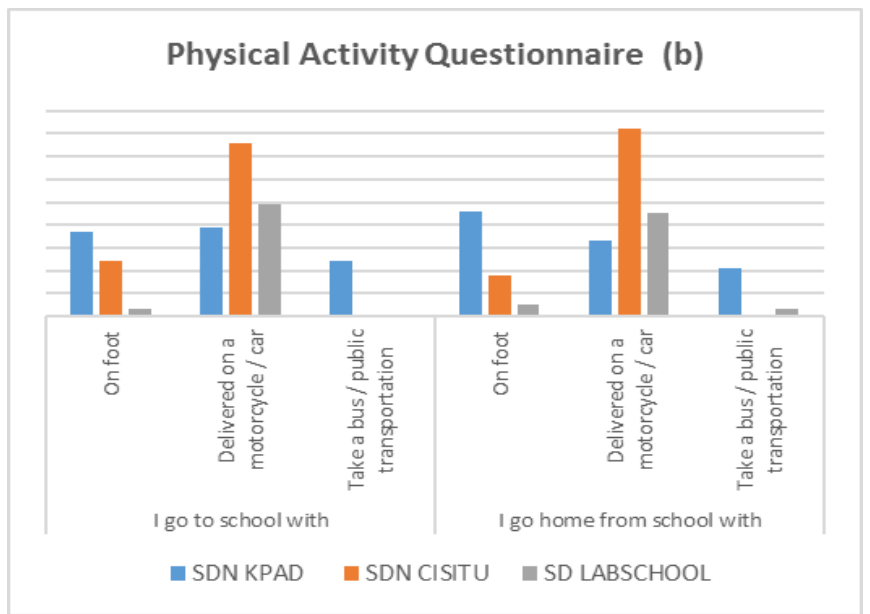

Fig. 5. Questionnaire results on physical activity (b).

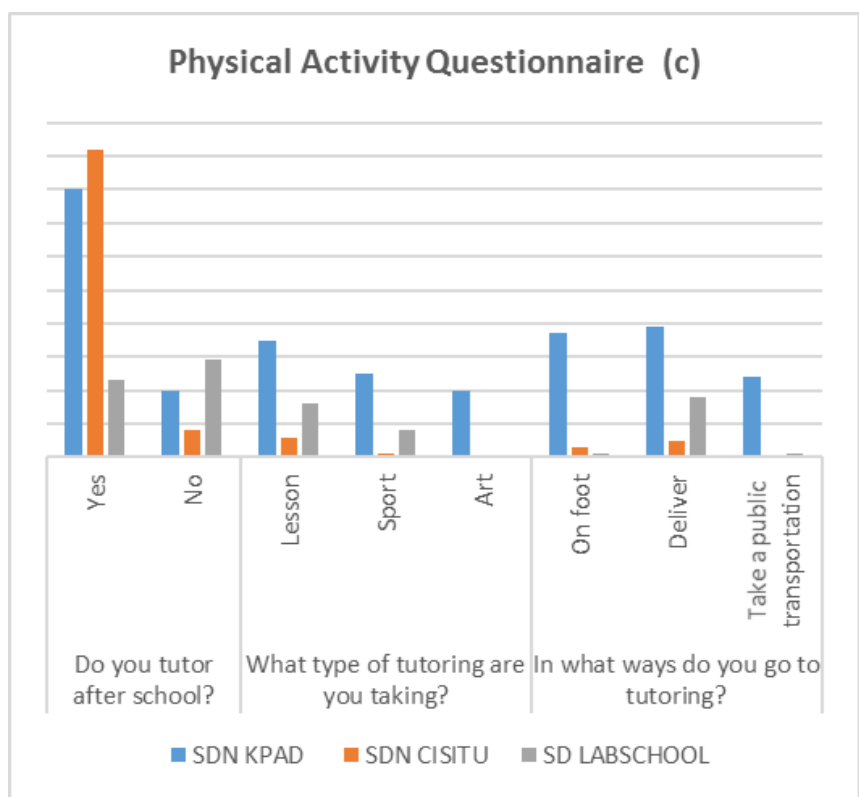

Fig. 6. Questionnaire results on physical activity (c).

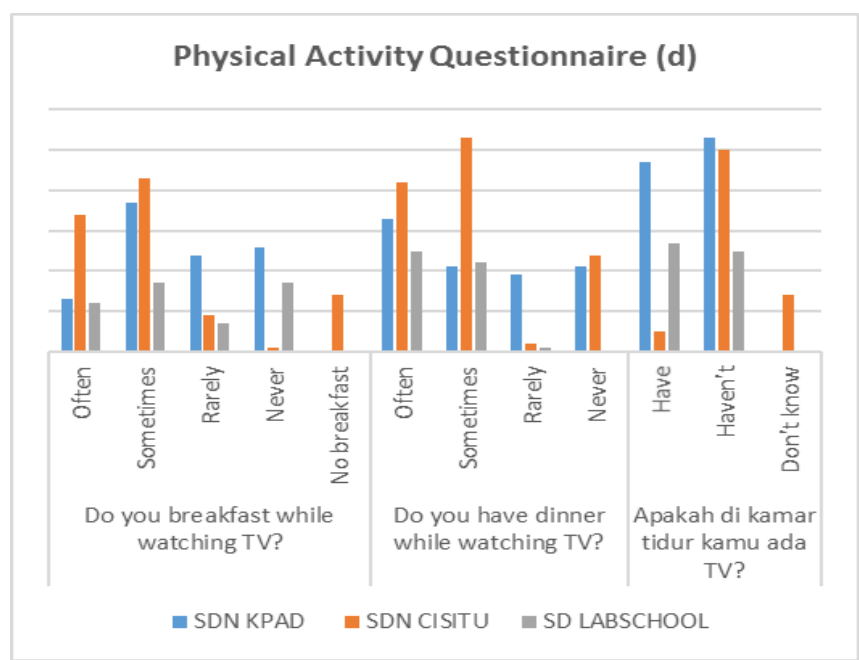

Fig. 7. Questionnaire results on physical activity (d).

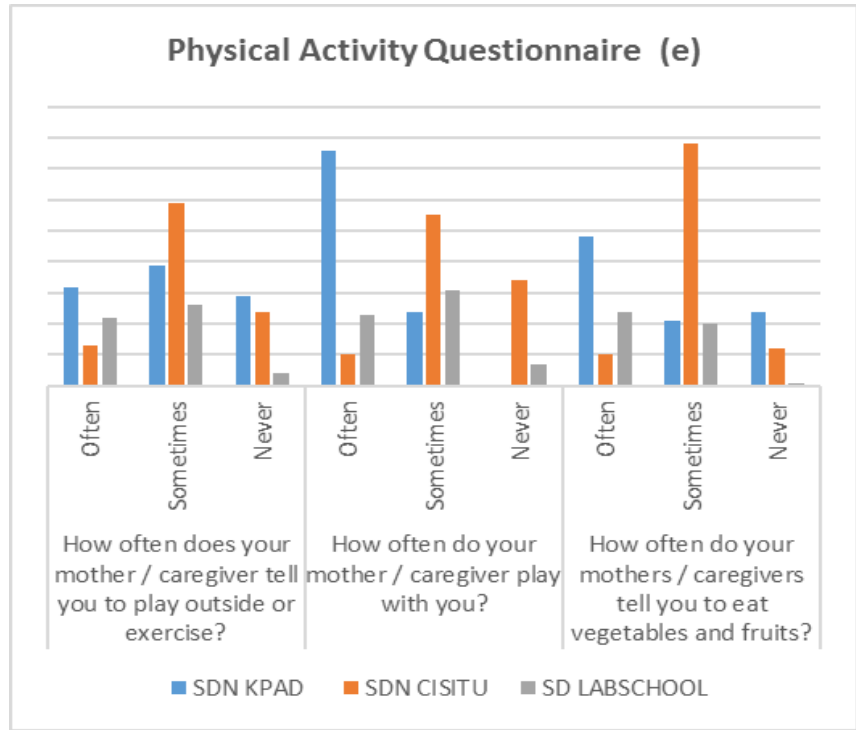

Fig. 8. Questionnaire results on physical activity (e).

Regarding physical activity performed by the children, Fig. 4, Fig. 5, Fig. 6, Fig. 7, and Fig. 8 reflect what they actually do in their daily life. In terms of the frequency of doing physical activity, it cannot be denied that most of the children did rather frequent physical activity. Many of them still run around the school yard during recess time, some of them still ride their bike, and some even do several physical activities at home. However, when they were asked of what kind of after school courses they take, only a few of them have a sport-related activities. Most of them take additional courses on the lessons such as Mathematics and English. In addition, only a few of them commute to schools. Their parents mostly take them to schools, either by cars or by motorcycles. Another fact supporting their lack of physical activity is that most of the respondents have their meal while watching TV in their rooms.

A study by Sirard proves that commuting to schools is such an effective way to promote elementary school students' physical activity [10]. By using ActiGraph, the students who commute to schools outperform those who do not in terms of physical fitness. Donnelly et al. also agree that physical activity should be implemented in early education, which is elementary education [11]. They further believe that physical activity should be combined by good nutirion to reach ideal healthy and active lifestyle.

\section{CONCLUSION}

It can be concluded that the index of physial activity of elementary school students in Bandung is still low. Thus, there needs to be a massive policy, particularly in the curriculum which is able to promote healthy and active lifestyle so that students are prepare to have lifelong physical activity.

\section{REFERENCES}

[1] R. R. Pate, "A national physical activity plan for the United States," Journal of Physical Activity and Health, vol. 6(Supplement 2), pp. S157, 2009 
[2] C. M. Ciotto and M. H. Fede, |PASS: Creating physically active school systems," Journal of Physical Education, Recreation and Dance, vol. 85(8), pp. 13-19, 2014.

[3] C. B. Corbin, "Physical activity for everyone: What every physical educator should know about promoting lifelong physical activity," Journal of teaching in physical education, vol. 21(2), pp. 128-144, 2002.

[4] S. Fairclough and G. Stratton, "Physical Activity Levels in Middle and High School Physical Education: A Review," Pediatric Exercise Science 17: pp. 217-36, 2005.

[5] L. Haerens, D. Kirk, G. Cardon, I. De Bourdeaudhuij, and M. Vansteenkiste, "Motivational profiles for secondary school physical education and its relationship to the adoption of a physically active lifestyle among university students," European Physical Education Review, vol. 16(2), pp. 117-139, 2010.

[6] A. Toffler, Future shock 1970. 1970, Sydney. Pan.

[7] R. P. Pangrazi and V. P. Dauer, "Dynamic Physical Education for Elementary School Children, 10 th Ed.," 1992, New York: Macmillan Publishing Company.
[8] D. L. Katz, C. S. Katz, J. A. Treu, J. Reynolds, V. Njike, J. Walker, ... and J. Michael, "Teaching healthful food choices to elementary schoo students and their parents: the Nutrition Detectives ${ }^{\mathrm{TM}}$ program," Journal of School Health, vol. 81(1), pp. 21-28, 2011.

[9] S. Kelder, D. M. Hoelscher, C. S. Barroso, J. L. Walker, P. Cribb, and S. $\mathrm{Hu}$, "The CATCH Kids Club: a pilot after-school study for improving elementary students' nutrition and physical activity," Public health nutrition, vol. 8(2), pp. 133-140, 2005.

[10] J. R. Sirard, J. W. Riner, K. L. McIver, and R. R. Pate, "Physical activity and active commuting to elementary school," Medicine and science in sports and exercise, vol. 37(12), pp. 2062-2069, 2005.

[11] J. E. Donnelly, D. J. Jacobsen, J. E. Whatley, J. O. Hill, L. L. Swift, A. Cherrington, ... and G. Reed, "Nutrition and physical activity program to attenuate obesity and promote physical and metabolic fitness in elementary school children," Obesity Research, vol. 4(3), pp. 229-243, 1996. 